\title{
Effectiveness of Sitz Bath Versus Infrared Ray Therapy on Level of Episiotomy Pain and Wound Healing Among Post Natal Mothers in Selected Hospital, Puducherry
}

\author{
Chandraleka $\mathbf{R}^{1}$, Manju Bala Dash ${ }^{2 *}$ and Felicia Chitra ${ }^{3}$ \\ ${ }^{1}$ Msc Nursing Student, Mother Theresa Post Gradute And Research Institute of Health Sciences, Puducherry, India \\ ${ }^{2}$ Prof. And Head Dept of OBG. MTPG\&RIHS, Mother Theresa Post Gradute And Research Institute of Health Sciences, Puducherry, \\ India \\ ${ }^{3}$ Principal. CON. MTPG\&RIHS, Mother Theresa Post Gradute And Research Institute of Health Sciences, Puducherry, India \\ *Corresponding author: Manju Bala Dash, Prof. And Head Dept of OBG. MTPG\&RIHS, Mother Theresa Post Gradute And Research \\ Institute of Health Sciences, Puducherry, India
}

\section{ARTICLE INFO}

Received: 杫 September 13, 2019

Published: September 19, 2019

Citation: Chandraleka R, Manju Bala Dash, Felicia Chitra. Effectiveness of Sitz Bath Versus Infrared Ray Therapy on Level of Episiotomy Pain and Wound Healing Among Post Natal Mothers in Selected Hospital, Puducherry. Biomed J Sci \& Tech Res 21(3)-2019. BJSTR. MS.ID.003605.

Keywords: Effectiveness; Sitz Bath; Infrared Ray Therapy; Postnatal Mothers

\section{ABSTRACT}

Background: In normal delivery process, the mother has to experience enormous pain to bring out the baby from their womb. The rate of episiotomy among the postnatal mothers in Nigeria is around $35.6 \%$ and in PrimiGravida mothers the rate was around 88.5\% and in Enugu, the rate of episiotomy was around $40.4 \%$ for women including Primi Para and in multipara. There are some of the pharmacological, non-pharmacological and complementary therapies for episiotomy pain and wound healing. Sitz Bath is warm water, shallow bath that cleans the perineum, which is the space in between the rectum and the vulva or scrotum. Infrared ray therapy increases the level of nitric oxide and thereby it leads to vasodilation of vessels which helps in healing the episiotomy wound and reduces the pain level.

Aim: The aim of the study was to evaluate the effectiveness of sitz bath and Infrared ray therapy on level of episiotomy pain and wound healing among the postnatal mothers admitted in selected hospital, Puducherry.

Methodology: A comparative study was conducted among mothers who gave birth to the baby with normal delivery and had episiotomy in selected hospital, Puducherry. Sample size was 90, selected through purposive sampling technique. The quantitative approach and Quasi experimental- pretest posttest with control group research design was used in this study. The data was collected through interview schedule from the subjects regarding their demographic and obstetrical variables, Universal pain assessment scale and REEDA scale were used to assess the level of episiotomy pain and wound healing among the postnatal mothers.

Result and Conclusion: The result shows that, the post-test mean score level of pain among experimental group II and the control group are $2.77 \pm 0.5,2.83 \pm 0.98$ and the calculated ' $\mathrm{t}$ ' value of $\mathrm{t}=0.33$ was found to be statistically significant at $\mathrm{p}<0.05$ level. For experimental group II and control group are $2.27 \pm 0.45,2.83 \pm 0.98$. The calculated unpaired ' $\mathrm{t}$ ' test value $\mathrm{t}=-2.85$ was found to be statistically significant at $\mathrm{p}<0.001$ level. The posttest mean score for level of episiotomy wound healing among experimental group I experimental group II are 1.07 $\pm 0.25,1.23 \pm 0.43$ and the calculated unpaired ' $\mathrm{t}$ ' test value of $\mathrm{t}=1.82$ was found to be statistically significant at $\mathrm{p}<0.001$. For experimental group I and control group are $1.07 \pm 0.25,1.27 \pm 0.45$ and the calculated unpaired ' $t$ ' test value of $\mathrm{t}=-2.12$ was found to be statistically significant at $\mathrm{p}<0.001$ level. From this study the researcher concluded that, both the sitz bath and infrared ray therapy was effective in reducing the level of pain and wound healing of episiotomy wound among the postnatal mothers. In that, the sitz bath is more effective in reducing the level of episiotomy pain and wound healing among the postnatal mothers. 


\section{Introduction}

"Giving birth is a powerful and life changing event with a lasting impact on women and their families". All women who are pregnant will undergo the process of delivery [1]. The process of delivery may be normal delivery, vacuum delivery, forceps delivery or caesarean section. During normal delivery process, the baby from the mother's womb is delivered through the vagina, and the episiotomy is performed to enlarge the birth canal by the health care provider [2]. During delivery, the mother has to experience enormous pain to bring out the baby from their womb. After delivery, the mother may experience perineal discomfort due to the episiotomy incision. A surgical incision which is made in the perineum to enlarge the birth canal at the time of crowing to deliver the baby without any complications is considered as episiotomy [3].

A Sitz Bath is a bath, in which a person is asked to sit in a water tub up to the hip level. A sitz bath is otherwise called as hip bath. The term "sitz bath" is derived from "the German word sitz bad", which means "A bath in which one sitz". Sitz bath is given by warm water or by cool water. Warm water sitz bath is recommended to reduce the pain, itching and discomfort $[4,5]$. Sitz Bath is warm water, shallow bath that cleans the perineum, which is the space in between the rectum and the vulva or scrotum. A sitz bath can also provide relief from pain or itching in the genital area. The befits or advantages of providing sitz bath includes relieving from perineal irritation, pain, swelling and it prevents from soreness, burning sensation around the perineum. Sitz bath is indicated for hemorrhoids, Ano-rectal infections and surgeries and for the vaginally delivered mother during postnatal period [6].

The infrared ray was the dry heat therapy which increases the level of nitric oxide and thereby it leads to vasodilation of vessels. It keeps the wound dry and reduces the pain level $[7,8]$. The rate of episiotomy among the postnatal mothers in Nigeria is around $35.6 \%$ and in PrimiGravida mothers the rate was around $88.5 \%$ and in Enugu, the rate of episiotomy was around $40.4 \%$ for women including Primi Para and in multipara. Nigeria is showing the lower rate of episiotomy wound among the postnatal mothers [9-11].

\section{Objectives}

a) To assess the existing Level of Episiotomy Pain and Wound Healing among the Experimental Group I (Sitz Bath), Experimental Group II (Infrared Ray Therapy) and Control Group Postnatal Mothers.

b) To assess the Level of Episiotomy Pain and Wound Healing among the Experimental Group I, II and Control Group after the intervention among the Postnatal Mothers.

c) To compare the Pre-test and Post-test Level of Episiotomy Pain and Wound Healing among the Experimental Group I, II and Control Group Postnatal Mothers. d) To correlate the Post-test Level of Episiotomy Pain and Wound Healing among the Experimental Group I, Experimental Group II Postnatal Mothers.

e) To associate the Post-test Level of Episiotomy Pain and Wound Healing with the selected Demographic and Obstetrical Variables of Postnatal Mothers.

\section{Methodology}

The present study was aimed to evaluate the effectiveness of Sitz bath versus Infrared ray therapy on level of episiotomy pain and wound healing among the postnatal mothers. In order to achieve the study objectives, a quantitative research approach and the Quasi experimental of pretest posttest with control group research design was used in this study [12]. The independent variable of this study was Sitz Bath and Infrared ray therapy and the dependent variable was level of episiotomy pain and wound healing among postnatal mothers. The study was conducted in a selected hospital at Puducherry. The population comprises of the mothers who have delivered the baby through spontaneous vaginal delivery with episiotomy wound in selected hospital at Puducherry. The mothers were selected according to the inclusion criteria. The sample size comprised of 90 mothers. The process of selection of sample from the entire population is considered as sampling technique. Purposive sampling technique was used in this study, the mothers who were in the first day of postnatal period were selected. Inclusion criteria of this study were

a) Mother who had normal or instrumental vaginal delivery with episiotomy.

b) Mother who were in the first day of postnatal period.

c) Mother who were willing to participate in the study.

d) Mother who were available at the time of data collection.

The tool was divided into four sections.

a) Section A: consists of demographic and obstetrical variables of the mothers including name, age, religion, educational status, occupation, income, residence, type of family.

b) Section B: consists of parity, type of instrumental delivery, type of incision, local anesthesia, number of superficial suture, length of episiotomy wound, number of perineal pads used per day, head circumference of the baby, time of beginning daily activities after delivery, appearance of the wound.

c) Section C: consists of REEDA scale.

d) Section D: consists of universal pain assessment scale. Data was collected from each mother after obtaining individual consent. 
Mothers were introduced about the study and researcher was collected the information by interview schedule and observation method. The pretest was done on day 1 and sitz bath was given to experimental group I, Infrared ray therapy was given to experimental group II and routine care was provided to the control group. The intervention was provided for five days twice a day and the posttest was done on day 5 .

\section{Result}

The result of the present study predicted the comparison of Pretest Level of Pain among the Postnatal Mothers in the Experimental Groups and control group. The Pretest mean score for level of pain among Experimental Group I and the Experimental Group II are $1.04 \pm 4.27,1.18 \pm 4.80$ and the calculated unpaired ' $t$ ' test value of $t=1.84$ and the ' $p$ ' value is 0.22 . The pretest mean score for level of pain among Experimental Group II and the Control Group are $1.18 \pm 4.80,1.12 \pm 3.97$ and the calculated ' $t$ ' value of $t=-2.78$ and the ' $\mathrm{p}$ ' value is 0.44 . The pre-test mean score for Experimental Group I and Control Group are 1.048 $\pm 4.27,1.12 \pm 3.97$. The calculated unpaired ' $\mathrm{t}$ ' test value of $\mathrm{t}=1.06$ and the ' $\mathrm{p}$ ' value is 0.69 . This indicates that, the mothers experience more pain due to episiotomy (Tables 1 \& 2) \& (Figure 1). Predicted that the Comparison of Posttest Level of Pain among the Postnatal Mothers in the Experimental Groups and Control Group. The Posttest mean score for level of pain among Experimental Group I and the Experimental Group II are $2.27 \pm 0.45,2.77 \pm 0.50$ and the calculated unpaired ' $t$ ' test value of $\mathrm{t}=4.054$ and the ' $\mathrm{p}$ ' value is 0.78 .

\section{Comparison of post -test level of pain among the postnatal mothers in the experimental groups (sitz bath group and Infrared ray group) compared to control group}

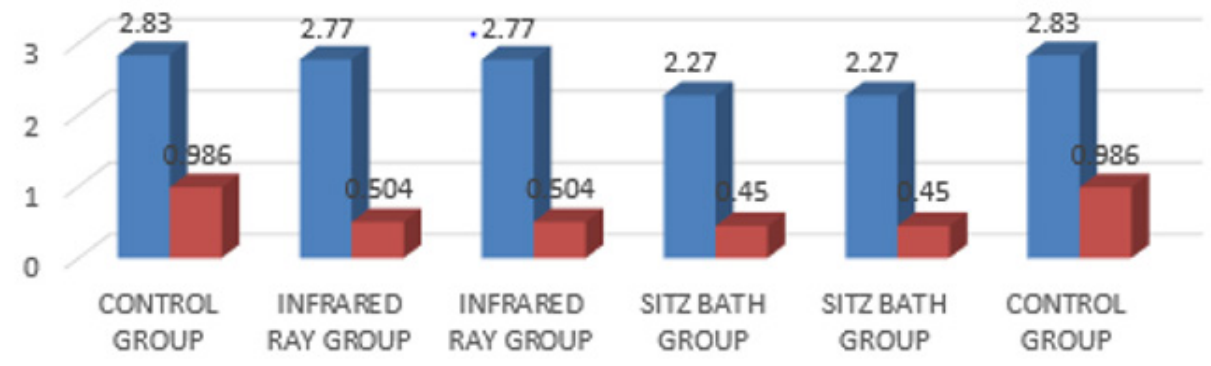

= MEAN = STANDARD DEVIATION

Figure 1: Comparison of Post-test Level of Pain among the Postnatal Mothers in the Experimental Groups and Control Group.

Table 1: Comparison of Pre-test Level of Pain among the Postnatal Mothers in the Experimental Groups and Control Group.

\begin{tabular}{|c|c|c|c|c|}
\hline Groups & Mean & SD & "t” Value Unpaired t-Test & p-Value \\
\hline Experimental Group I & 4.27 & 1.04 & \multirow{2}{*}{0.22} \\
\hline Experimental Group II & 4.8 & 1.18 & -2.78 & \multirow{2}{*}{0.44} \\
\hline Experimental Group II & 4.8 & 1.18 & 1.06 & \multirow{2}{*}{0.69} \\
\hline Control Group & 3.97 & 1.12 & 1.04 & \\
\hline Experimental Group I & 4.27 & 1.129 & & \\
\hline Control Group & 3.97 & & & \\
\hline
\end{tabular}

Table 2: Comparison of Post-test Level of Episiotomy Pain among the Postnatal Mothers in the Experimental Groups and Control Group.

\begin{tabular}{|c|c|c|c|c|}
\hline Groups & Mean & SD & “t” Value Unpaired t-Test & p-Value \\
\hline Experimental Group I & 2.27 & 0.45 & 4.05 & 0.78 \\
\hline Experimental Group II & 2.77 & 0.5 & 0.33 & $0.003^{*}$ \\
\hline Experimental Group II & 2.77 & 0.5 & $(\mathrm{~S})$ \\
\hline Control Group & 2.83 & 0.98 & -2.85 & $0.001^{*}$ \\
\hline Experimental Group I & 2.27 & 1.129 & $(\mathrm{~S})$ \\
\hline Control Group & 2.83 & 0.98 & & \\
\hline
\end{tabular}

Note: ${ }^{*}$ p $<0.05$ significant, ${ }^{* *}$-p $<0.001$ and ${ }^{* * *}$-p $<0.0001$ highly significant. 
The posttest mean score for level of pain among Experimental Group II and the Control Group are $2.77 \pm 0.5,2.83 \pm 0.98$ and the calculated ' $t$ ' value of $t=0.33$ was found to be statistically significant at $\mathrm{p}<0.05$ level. The posttest mean score for experimental group I and control group are $2.27 \pm 0.45,2.83 \pm 0.98$. The calculated unpaired ' $t$ ' test value of $t=-2.85$ was found to be statistically significant at $p<0.001$ level. This indicates that, sitz bath and infrared ray therapy are significant in reducing the level of episiotomy pain among the postnatal mothers (Table 3) \& (Figure 2) predicted that the Comparison of Post-test Level of Wound Healing among the Postnatal Mothers in the Experimental Groups and Control Group. The Posttest mean score for level of wound healing among
Experimental Group I and the Experimental Group II are $1.07 \pm 0.25$, $1.23 \pm 0.43$ and the calculated unpaired ' $t$ ' test value of $t=1.82$ was found to be statistically significant at $p<0.001$ level. The posttest mean score for level of wound healing among experimental group II and the control group are $1.23 \pm 0.43,1.27 \pm 0.45$ and the calculated ' $t$ ' value of $t=0.29$ and the ' $p$ ' value is 0.59 . The Posttest mean score for experimental group I and control group are 1.07 \pm 0.25 , $1.27 \pm 0.45$ and the calculated unpaired ' $t$ ' test value of $t=-2.12$ was found to be statistically significant at $\mathrm{p}<0.001$ level. This indicates that, Sitz Bath and Infrared Ray Therapy are Significant in Healing the Episiotomy Wound among the Postnatal Mothers.

\section{comparison of post -test level of wound healing among the postnatal mothers in the experimental groups (sitz bath group and Infrared ray group) compared to control group}

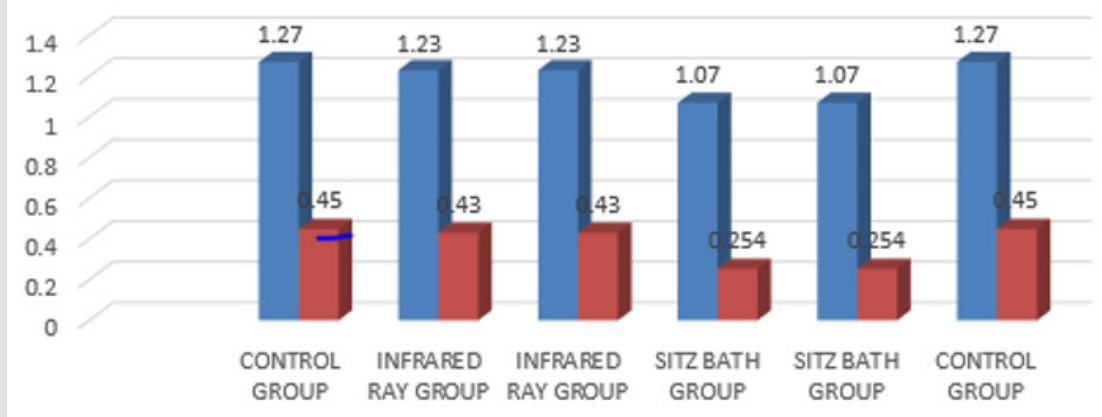

- MEAN —STANDARD DEVIATION

Figure 2: Comparison of Posttest Level of Wound Healing among the Postnatal Mothers in Experimental Groups and Control Group.

Table 3: Comparison of Post-test Level of Wound Healing among the Postnatal Mothers in the Experimental Groups and Control Group.

\begin{tabular}{|c|c|c|c|c|}
\hline Groups & Mean & SD & "t" Value Unpaired t-Test & $\mathrm{p}$-Value \\
\hline Experimental Group I & 1.07 & 0.25 & \multirow{2}{*}{1.82} & \multirow{2}{*}{$\begin{array}{c}0.000^{*} \\
(\mathrm{~S})\end{array}$} \\
\hline Experimental Group II & 1.23 & 0.43 & & \\
\hline Experimental Group II & 1.23 & 0.43 & \multirow{2}{*}{0.293} & \multirow{2}{*}{0.599} \\
\hline Control Group & 1.27 & 0.45 & & \\
\hline Experimental Group I & 1.07 & 0.25 & \multirow{2}{*}{-2.12} & \multirow{2}{*}{$\begin{array}{c}0.000 * \\
\text { (S) }\end{array}$} \\
\hline Control Group & 1.27 & 0.45 & & \\
\hline
\end{tabular}

Note: ${ }^{*}$-p $<0.05$ significant, ${ }^{* *}$-p $<0.001$ and ${ }^{* * *}$-p $<0.0001$ Highly significant.

(Table 4) exhibits that the correlation between Posttest Mean Score for Level of Episiotomy Pain and Wound Healing among the Postnatal Mothers in the Experimental Group I and Experimental Group II. The posttest mean score for level of pain and wound healing are $2.27 \pm 0.45,1.07 \pm 0.25$ and the calculated karlpearson's correlation value of ' $r$ ' is 0.443 was statistically found to be significant at $\mathrm{p}<0.01$ level, $2.27 \pm 0.50,1.23 \pm 0.43$ and the calculated karlpearson's correlation value of ' $r$ ' is 0.41 was statistically found to be significant at $\mathrm{p}<0.05$ level in the experimental group I and experimental group II respectively. There is a positive correlation $(r=0.443$ and $r=0.419)$ between level of episiotomy pain and wound healing in Experimental Group I and Experimental group II respectively. In experimental group II, only number of superficial sutures is showing significant association at $p<0.001$ level in posttest level of episiotomy pain. In posttest level of wound healing only number of superficial sutures is showing significant association at $\mathrm{p}<0.001$ level in experimental group II. 
Table 4: Comparison of Post-test Level of Wound Healing among the Postnatal Mothers in the Experimental Groups and Control Group.

\begin{tabular}{|c|c|c|c|c|c|}
\hline Groups & Variables & Mean & SD & "r" Value & p-Value \\
\hline \multirow{2}{*}{ Experimental Group I } & Level of Pain & 2.27 & 0.45 & \multirow{2}{*}{0.44} & \multirow{2}{*}{$\begin{array}{c}0.014^{*} \\
(\mathrm{~S})\end{array}$} \\
\hline & Level of Wound Healing & 1.07 & 0.25 & & \\
\hline \multirow{2}{*}{ Experimental Group II } & Level of Pain & 2.77 & 0.5 & \multirow{2}{*}{0.41} & \multirow{2}{*}{$\begin{array}{c}0.021^{*} \\
(\mathrm{~S})\end{array}$} \\
\hline & Level of Wound Healing & 1.23 & 0.41 & & \\
\hline
\end{tabular}

Note: ${ }^{*}$-p $<0.05$ significant, ${ }^{* *}$-p $<0.001$ and ${ }^{* * *}$-p $<0.0001$ Highly significant.

\section{Discussion}

The result of the present study showed that, the Pre-test Level of Episiotomy Pain, in that majority of $14(46.7 \%)$ mothers had severe pain, $12(40 \%)$ mothers had worst possible pain and $12(40 \%)$ mothers had moderate pain and the Pre-test mean score for level of pain are $4.27 \pm 1.048,4.80 \pm 1.18$ and $3.97 \pm 1.12$ in the Experimental Group I, Experimental Group II and Control Group respectively. The Post-test Level of Episiotomy Pain, in that majority of 22(73\%) mothers had mild pain, 21(70\%) mothers had moderate pain and $14(46.7 \%)$ mothers had mild pain, and the Post-test mean score for level of pain are $2.27 \pm 0.450,2.77 \pm 0.504$ and $2.83 \pm 0.986$ in the Experimental Group I, Experimental Group II and Control Group respectively.

The present study was supported with the study conducted by Seethi Suseela conducted a study to evaluate the "Effectiveness of Sitz bath in reduction of episiotomy pain among 60 postnatal mothers in selected hospitals, Kolar District, Karnataka. The result shows that the sitz bath was more effective in reducing the level of episiotomy pain among postnatal mothers [13]. The Pre-test Level of Episiotomy Wound Healing, in that majority of 30(100\%), $30(100 \%)$ and $30(100 \%)$ mothers had normal wound and the Pretest mean score for level of episiotomy are 1.00,1.00 and 1.00 in the Experimental Group I, II and Control Group respectively. The Post-test Level of Episiotomy Wound Healing, in that majority of 28(93.3\%), 23(76.7\%) and 22(73.3\%) mothers had normal wound healing and the Post-test mean score for level of episiotomy are $1.07 \pm 0.254,1.23 \pm 0.430$ and $1.27 \pm 0.450$ in the Experimental Group I, II and Control Group respectively. The present study was supported with the study conducted by Jyoti Kapoor, Rita (2018) conducted a "quasi experimental study on effectiveness of medicated and non medicated sitz bath on episiotomy wound healing among 40 postnatal $\mathrm{m}$. yothers". The result shows that, both non medicated and medicated sitz bath was effective. In that, medicated sitz bath was more effective in healing the episiotomy wound [14].

The present study was supported with the study conducted by Amandeep (2014) conducted a study on "Effectiveness of sitz bath on episiotomy pain and wound healing among 60 postnatal mothers in selected hospital at Ludhiana, Punjab. The result shows that, the pretest mean score for pain was $5.02 \pm 2.17$ and the post-test mean score was $0.73 \pm 0.78$ in the experimental group, in the control group the pretest mean score was $4.90 \pm 2.33$ and the post test score was $2.73 \pm 1.50$. For wound healing in experimental group, the pretest mean score was $8.26 \pm 2.03$ and the post test score was $2.07 \pm 0.65$, in the control group the pretest mean score was $7.73 \pm 1.61$ and the post-test mean score was $3.23 \pm 1.47$. this study concluded that the sitz bath is effective in reducing episiotomy pain and improving wound healing process among the postnatal mothers [15].

The post-test illustrates that sitz bath is more effective in reducing the episiotomy pain and improving the wound healing when compared to infrared ray therapy. In control group, the postnatal mothers had delayed wound healing and experiencing more pain. The present study was supported with the study conducted by Kaur Sukhwinder et al. conducted a "comparative study to evaluate the effectiveness of Infrared ray therapy versus sitz bath on level of episiotomy pain and wound healing among 60 postnatal mothers in selected hospital, Chandigarh". The result shows that, the Infrared ray therapy and sitz bath are more effective in reducing the episiotomy pain and improving the wound healing. In that, sitz bath is more effective on episiotomy pain and wound healing among postnatal mothers [16].

\section{Conclusion}

From this study the researcher concluded that, both the sitz bath and infrared ray therapy was effective in reducing the level of pain and wound healing of episiotomy wound among the postnatal mothers. In that, the sitz bath is more effective in reducing the level of episiotomy pain and wound healing among the postnatal mothers. So, this method of intervention was routinely carried by the staff nursing and to teach the mothers to perform the sitz bath in their home itself.

\section{Recommendation}

Based on the result of the study and the experience of the researcher the following recommendations are made

a) Replication of the study may be done with the large samples in different settings to generalize the study findings.

b) This study can be conducted by using probability sampling technique to generalize the result findings more effectively.

c) This study can be conducted in community setting. 


\section{References}

1. Pore SY (2014) Effectiveness of moist heat and dry heat application on healing of episiotomy wound. Asian Journal of Multidisciplinary studies 2(7): 225-236.

2. Suseela S (2012) Reducing episiotomy pain through sitz bath. Nightingale Nursing Times 8(5): 52-56.

3. Cindiya Jobson Wilbert (2015) effectiveness of cold gel pad therapy versus infrared light therapy on episiotomy pain and wound healing process among postnatal mothers, Ethiopia. International journal of science and research pp. 1114-1120.

4. https://en.wikipedia.org/wiki/Sitz_bath

5. Kaur S, Sheroron P (2014) comparison of Infrared Light Therapy Vs Sitz bath on episiotomy in terms of wound healing and intensity of pain among postnatal mothers. International Journal of Nursing care 4(1): 37-41.

6. Tian C (2018) postpartum sitz bath benefits.

7. Horwitz, Lon R DPM, CWS Thomas J Burke, Dale carnegia DPM (1999) Augmentation of wound healing using Monochromatic Ingrared energy 'Exploration of a New Technology for Wound Management. J Advances in wound care 12(1): 35-40

8. Gabriel JF (2007) FisikaKedokteran. Jakarta: EGC pp.131-132.

ISSN: 2574-1241

DOI: 10.26717/BJSTR.2019.21.003605

Manju Bala Dash. Biomed J Sci \& Tech Res

(C) 7 This work is licensed under Creative

Submission Link: https://biomedres.us/submit-manuscript.php
9. Onah HE, Akani CI (2004) Rates and predictors of episiotomy in Nigerian Women. Trop J ObstetGynaecol 21(1): 44-45.

10. Sule ST, Shittu SO (2003) Puerperal complications of episiotomies at Ahmadu Bello University Teaching Hospital, Zaria, Nigeria. East Afr Med J 80(7): 351-356.

11. Inyang Etoch CE, Umoiyoho AJ (2012) The practice of episiotomy in a university teaching hospital in Nigeria. Int J Med Biomed Res 1(1): 6872.

12. Polit, Hungler (2004) Nursing research-principles and practice. $7^{\text {th }}$ (edn). Philadelphia: Lippincott.

13. Seethi Suseela (2015) Effectiveness of sitz bath in reduction of episiotomy pain among postnatal mothers. Karnataka pp. 1-24.

14. Jyoti Kapoor, Rita (2018) Medicated and nonmedicated sitz bath on episiotomy wound healing among postnatal mothers. Jammu 4(2): 9296.

15. Amandeep, Nidhi Sagar, Mamta (2014) Effect of sitz bath in reduction of episiotomy pain and wound healing among postnatal mothers at Punjab. India 7(2): 12461-12463.

16. SukhwinderKaur (2014) Infrared ray therapy vs sitz on episiotomy in terms of wound healing and intensity of pain among postnatal mothers, India.

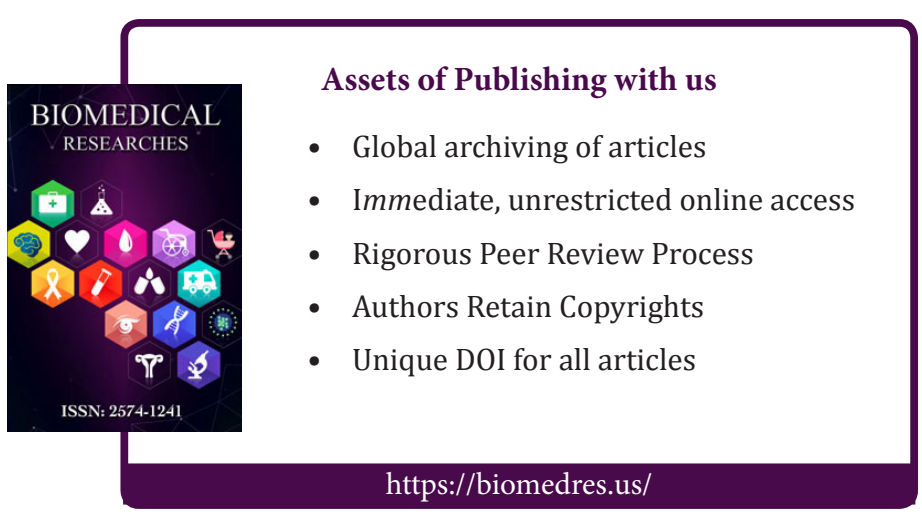

